\title{
Entrevista com Arjun Appadurai
}

Interview with Arjun Appadurai

Concedida a Bianca Freire-Medeiros e

Mariana Cavalcanti

Berlim, 13 de junho de 2008

Arjun Appadurai nasceu em Bombaim, hoje Mumbai, e ali viveu até se mudar para Boston, onde se graduou pela Universidade Brandeis. Mestre, em 1970, e doutor, em 1973, pelo Programa de Pensamento Social da Universidade de Chicago, após uma breve passagem pela Universidade da Pennsylvania, retornou a Chicago como professor do Departamento de Antropologia. Aí permaneceu até 2001, quando aceitou um convite da Universidade de Yale. De lá, lecionou na New School até tornar-se professor de Mídia, Cultura e Comunicação na New York University, onde permanece até hoje.

Bianca Freire-Medeiros é pesquisadora do CPDOC/FGV e professora da Escola Superior de Ciências Sociais da FGV e do Programa de Pós-Graduação em História, Política e Bens Culturais do CPDOC, Rio de Janeiro (bianca.freire.medeiros@fgv.br).

Mariana Cavalcanti é pesquisadora do CPDOC/FGV e professora da Escola Superior de Ciências Sociais da FGV e do Programa de Pós-Graduação em História, Política e Bens Culturais do CPDOC, Rio de Janeiro (mariana.cavalcanti@fgv.br). 
Appadurai vem publicando livros que marcam e, de certo modo, contribuem para a definição das grandes problemáticas das ciências sociais a cada década. Nos anos 80, foi $A$ vida social das coisas, coletânea de 1986, recentemente publicada em português (EdUFF, 2008). O livro conta com uma longa Introdução que continua sendo um dos textos centrais para os debates contemporâneos acerca das relações entre bens e mercadorias, antropologia do consumo, e cultura material. Nos anos 90, a publicação de Modernity at Large (cuja ausência de edição no Brasil é lamentável) chamou atenção para a necessidade de se compreender os aspectos culturais da globalização, fenômeno até então analisado como concernente à esfera econômica ou financeira e cujos efeitos eram sentidos no campo da cultura. Nesta obra, Appadurai mostra como as dimensões culturais são aspectos constitutivos da globalização, e não fenômenos residuais. Os atentados terroristas de 11 de setembro de 2001 trouxeram à tona, uma vez mais, a atualidade de suas pesquisas, uma vez que, no final dos anos 90 , ele começara a ocupar-se do estudo de conflitos étnicos e genocídios em diversas partes do mundo. O resultado foi a publicação do pequeno livro de ensaios Fear of Small Numbers.

Simultaneamente, Appadurai passou a investir também nos estudos de movimentos sociais. Em 2001, fundou a Partners for Urban Knowlege, Action and Research (Pukar), organização não governamental que tem por objetivo integrar o conhecimento acadêmico à militância de base na questão da moradia. Appadurai foi fundador, juntamente com sua esposa, Carol Breckenridge, falecida em outubro de 2009, da revista Public Culture que, desde seu primeiro número publicado em 1988, fomenta debates acerca de questões compartilhadas entre as disciplinas das ciências sociais, filosofia, estudos culturais e comunicação. Até hoje, é uma das revistas mais respeitadas e lidas na academia norte-americana.

A entrevista que se segue foi realizada no Hotel Grand Esplanade, por ocasião do evento Eighth Roundtables on Transnationality: Identities, Governance and Empowerment in Megacities, em que Appadurai proferiu a conferência inaugural.

Poderíamos começar falando sobre a publicação, ainda que tardia, de A vida social das coisas em português. Imagino que seja estranho falar sobre um projeto concluído há tanto tempo, mas seria ótimo se pudéssemos ouvi-lo um pouco sobre o livro.

- Posso dizer algumas coisas de interesse a quem lê agora um livro editado há mais de 20 anos. A primeira é que este livro continua vendendo bastante, inclusive no mundo anglo-saxão, onde esteve acessível desde o início. Ou seja, o livro tem uma espécie de público leitor que se renova de modo contínuo. Isso me 
deixa bastante satisfeito, e mostra não só que o tema permanece fundamental e interessante, como também que as colaborações que o constituem têm apelos múltiplos e interdisciplinares. Isso não mudou, e tenho certeza que as pessoas trazem problemas diferentes para o livro e o deixam com ferramentas, ideias ou reações diferentes.

Esse é o primeiro ponto relevante: apesar de os leitores brasileiros possivelmente só o verem agora, estarão se juntando a uma certa geração de leitores em inglês e em outras línguas. Uma observação correlata é que os temas do livro são, de certo modo, perenes para a antropologia e disciplinas afins. E assuntos como a tensão contínua entre o dom e a mercadoria - ou, de modo mais sutil, a relação entre seres humanos e objetos - não correm o risco de serem esgotados ou encerrados porque são básicos.

Pessoalmente, meu interesse continuado pelo livro ocorre por dois motivos. O primeiro é que o interesse que eu tinha quando estava preparando $A$ vida social das coisas por temas como circulação, conhecimento e assim por diante, era, na verdade, antecipatório do que estava por vir. Eu já me interessava, então, por temas que articulei de modo mais aprofundado dez anos mais tarde, em Modernity at Large, com o estudo de fluxos globais, entre outras coisas. Mas é claro que vejo isso numa visão retrospectiva. Na época em que escrevi Modernity at Large ou melhor, que terminei Modernity at Large -, não tinha consciência disso; pensava que era um momento diferente e um tema diferente. De algum modo, porém, percebo que a problemática, por assim dizer, da circulação e dos circuitos, o modo como eles se formam e o que representam para a agência humana com relação a fluxos de mercadorias, todos esses temas são desenvolvidos em Modernity at Large, e figuram nas minhas preocupações e nas de outras pessoas desde então.

A segunda razão pela qual continuei a me interessar por $A$ vida social das coisas talvez seja mais geral, mais abstrata. Considero essa obra uma porta de entrada em um campo que estou chamando - mas, talvez, outras pessoas tenham outros nomes para ele - de "antropologia da materialidade". No próximo semestre, vou ministrar um curso com esse título e que vai contar com a participação, durante um mês, do meu amigo e colega Peter Van der Veer, da Holanda. Estamos tentando ampliar a preocupação com as coisas para abrir a questão mais ampla da realidade. Fiz um pequeno esforço nesse sentido em uma coletânea publicada por dois colegas holandeses chamada "Repensando a Mercantilização", que faz uma referência à Vida social das coisas. Tenho um pequeno ensaio nessa coletânea e nele tento discutir como é necessário refletir de modo mais abstrato, ou seja, ter uma compreensão mais aberta sobre a vida material em si mesma, especialmente em um mundo em que vários modos de virtualidade passam a nos atingir. No entanto, creio que muitos de nós relutamos em criar uma grande divisão entre o virtual e o cibernético. 
Trata-se, então, de um retorno a um tema clássico da antropologia desde Mauss?

- Sim, mas é também por isso que eu digo que se trata do mesmo tema. Contudo, ao invés de confiná-lo, ou seja, de pensar primordialmente em termos de dons e mercadorias, podemos reconhecer que dons e mercadorias são, em si mesmas, categorias importantes, marcadas no âmbito de um problema mais geral, tal como Braudel, ou talvez Marx, os tinham pensado, que é o da vida material em si. E agora podemos estender e problematizar a questão da materialidade por causa dessa tensão com a virtualidade, que também sabemos ser uma coisa com efeitos, com limites, com distribuições, e toda a sorte de qualidades que associamos, de modo estreito, à materialidade. Essas propriedades também pertencem ao virtual, e nos convidam a expandir nossa noção do que a materialidade envolve.

Outra questão à qual não prestei muita atenção quando editávamos $A$ vida social das coisas diz respeito à mídia e às mediações. A mediação é um processo que, por sua própria natureza, abre para a questão da materialidade porque se refere, entre outras coisas, a uma ação à distância, outro problema clássico antropológico, presente nos estudos da magia. Já a mídia remete aos efeitos sobre as distâncias e esses efeitos são, frequentemente, materiais, corporificados etc. Em suma, pensar sobre a materialidade, e não apenas a cultura material, é um bom ponto de partida. Ver que as coisas são parte da cultura material, mas que a cultura material, ela mesma, amplia a questão da materialidade. Essa é uma vertente de estudos que $A$ vida social das coisas continua sendo, para mim, um ponto de referência. Como a vida material funciona em geral, quais são seus princípios e como podemos - enquanto antropólogos, enquanto cientistas sociais - desenvolver idéias mais amplas, mais inclusivas, sobre os objetos, ou seja, que os objetos sejam parte de um conjunto mais amplo de materialidades.

Isso nos conduziria, na minha opinião, a um dos temas centrais de seu pensamento ao longo do tempo. Refiro-me ao papel da imaginação como força social, ou, como o senhor mesmo diz, a imaginação como um fato social. Poderíamos dizer que a questão é pensar a imaginação com uma certa materialidade?

- Exatamente! Essa pergunta é ótima. Elaborei a ideia da imaginação como fato social no início dos anos 90, que culminou nas afirmativas que fiz em 1996, em Modernity at Large, no qual a imaginação constitui, talvez, a ideia central ou motriz. Nessa época, não tinha consciência da conexão dessa idéia $\operatorname{com} A$ vida social das coisas, mas você está totalmente correta em dizer que, então, eu já não queria ver a imaginação figurar como uma faculdade individual, ou, se quiser, mental, ou como algo separada de efeitos sociais. Eu já estava, creio, tentando enxergar como a imaginação se materializava. 
Assim, hoje eu retornaria à $A$ vida social das coisas tendo em mente o problema da imaginação, que continua a me preocupar, só que menos em termos da questão do imaginário e de realidades imaginadas, que foi o modo como o percebi naquela época, ainda que ache isso muito rico e relevante. Hoje, porém, as minhas idéias sobre imagem e representação seguem em outra direção. Recentemente, um estudante colombiano da New School escreveu um trabalho em um curso que ministrei com minha esposa, Carol Breckenridge, sobre a distância significativa entre a ideia de imagem e a ideia de representação. Nós tendemos a usar esses termos como se eles nomeassem a mesma coisa, mas são diferentes em aspectos muito importantes, e um desses diz respeito às suas respectivas materialidades. A representação se distancia formalmente de algo mais material do que ela própria. Assim, podemos pensar a imagem como algo talvez mais profundamente material. Em suma, as imagens têm mais materialidade do que nós atribuímos a elas.

Creio que um componente do nexo entre objeto, ou coisa, e imaginação no meu próprio pensamento, traria temas não só de mídia e mediação, mas de visualidade, imagem, representação, seja em formas estáticas, tais como as fotografias, seja em movimento, como no cinema. Temos práticas imagéticas muito importantes em que o espectador/observador e o observado/visto encontram-se em uma relação profundamente informada por muitas materialidades, incluindo a materialidade corporificada do espectador e as materialidades corporificadas da imagem. É nessa direção que vejo, ao menos em parte, o futuro do estudo da imaginação como prática social. É a força social da imaginação, produzida como coisa central, material.

$E$ a dimensão política de A vida social das coisas?

- Esta seria outra questão importante no caminho trilhado desde $A$ vida social das coisas até Modernity at large e os trabalhos sobre a globalização e o papel da imaginação. Poderíamos pensar, por exemplo, em ideias como caminhos e desvios, já presentes em $A$ vida social das coisas. O que eu chamava de caminhos e desvios nesse livro podem hoje ser transpostos para questões que envolvem o que chamamos de fluxos e obstáculos em processos globais. Onde encontramos os obstáculos, onde estão os pontos de disjunção desses processos globais?

Hoje eu colocaria a questão do seguinte modo: se falamos de globalização, se observamos os fluxos culturais globais, com suas irregularidades, os impedimentos para acessá-los e o acesso imperfeito e desigual que as pessoas têm a esses circuitos - tudo isso tem a ver com o que eu concebia como "caminhos e desvios". E isso pode ser generalizado, pois os padrões de fluxo de coisas têm a ver com o que chamo de a política do valor e o lugar das elites, com o fato de que essas coisas têm uma economia, que essa economia é uma economia política e 
que nem tudo é possível a qualquer momento para todas as pessoas. Tudo isso tem a ver com o estudo da globalização.

Muitos estudiosos da globalização perguntariam: "por que precisamos disso?" Afinal, todos sabemos que a globalização é, de certo modo, inerentemente produtora de desigualdades, que ela não constitui um processo justo ou plano, como diria Friedmann. O que eu teria a dizer sobre isso é que, sim, a globalização produz desigualdades, mas muitas das imagens construídas sobre essa produção de desigualdade sob regimes de globalização ou sob o neoliberalismo são explicações formuladas a partir de modelos verticais ou nacionais e estáticos. Se observarmos o movimento das coisas, dos fluxos, e estendermos esse movimento a temas como fluxos globais de mercadorias ou tráfico de pessoas, de órgãos, tudo isso traz à tona dinâmicas de poder, de exclusão e mesmo de vitimização. Nada disso, porém, tem lugar no interior de qualquer pirâmide de distribuição de desigualdades dentro de um Estado-nação.

Em alguns trabalhos desenvolvidos no começo da minha carreira cheguei a fazer uma distinção que talvez sirva, hoje, para responder à questão sobre o que uma visão calcada nas ideias trabalhadas em $A$ vida social das coisas pode contribuir para o estudo da globalização e de desigualdades. Trata-se de uma distinção pouco conhecida, que fiz há muito tempo atrás, em um estudo sobre agricultura na Índia, e que nunca levei às últimas consequências. Nesse estudo, minha intenção era confrontar o trabalho etnográfico e trabalhos estatísticos em vilarejos indianos com os dados do censo nacional. É uma questão que afeta a todos: o que, às vezes, pensamos como oposição entre pesquisas quantitativas, o olhar micro versus o macro etc.

Eu argumentava, naquele trabalho, que a tensão mais profunda no estudo das desigualdades se dava entre o que podemos chamar de abordagens distributivas e as abordagens relacionais. Se olharmos para um simples e único vilarejo, como foi o caso do meu estudo, é possível afirmar que os fazendeiros precisam de gado para arar a terra, e havia menos gado do que famílias que viviam da agricultura. Há, pois, uma questão distributiva: digamos, 20 famílias têm gado e 120 não o possuem. É uma medida simples. Na prática, porém, os bois das famílias mais abastadas eram compartilhados com as famílias mais pobres. Mas obviamente, quando todas as famílias precisam do gado, as mais pobres ficavam sem porque o tempo de arar tornava-se uma questão crucial. Essa, contudo, era uma forma relacional de desigualdade, que não tinha nada a ver com ter ou não ter; tratava-se, isso sim, de uma relação de acesso.

Esse é um exemplo simples, mas se você o multiplica por cem, pode-se dizer que a desigualdade situa-se, às vezes, no terreno das coisas relacionais. Não se trata meramente da distribuição de casas, de energia elétrica, de educação, de saúde, e de todas as coisas distributivas, mas sim dos lugares da desigualdade. 
Pode parecer que eu estou me desviando do tema, mas a qualidade relacional das coisas tem a ver com seus fluxos. Por exemplo, o tráfico de órgãos é um fenômeno altamente relacional: é um fígado em Madras relacionado a uma necessidade em Minnesota. Não é passível de ser representado em um mapa estático de distribuição de desigualdades, seja nos Estados Unidos, seja na Índia. Isso simplesmente não funciona. Você poderia até fazê-lo de modo indireto, e afirmar que por causa da distribuição global entre ricos e pobres, há pessoas que podem arcar com certos custos, que há uma cadeia de oferta etc. Mas nada disso permite capturar o fato de que há um tráfico que conecta essas duas coisas.

Esse tráfico produz uma terceira, ou outra, esfera de desigualdades, que não diz respeito apenas às desigualdades entre a Índia e os Estados Unidos. É um terceiro espaço de desigualdade, que tem a ver com o órgão e seu movimento. Essa direção pode explicar porque a circulação de coisas e a vida social de, digamos, um órgão, no sentido que propus em 1986, podem ser iluminadas por meio de um olhar para as más distribuições, mas que têm a ver com novas formas de circulação. O foco nos processos de circulação é um dos meus maiores interesses.

No momento estou lidando com uma série de ideias que podem ser provisoriamente formuladas da seguinte maneira: o que precisamos, mas ainda não dispomos, é de uma abordagem que conecte as formas ou os circuitos de circulação com a circulação das formas. Como romances, por exemplo. Temos romances, temos constituições, temos toda a sorte de formas em circulação, mas essas formas só podem ser compreendidas em relação aos circuitos de circulação em si mesmos. Temos, pois, formas de circulação e a circulação de formas. É essa a tradução que eu faria da problemática que vem desde Marx, tendo em vista o que sabemos hoje. $\mathrm{E}$ isso, de certo modo, engloba a imaginação, mas também nos traz de volta à relação entre as coisas, a infusão das características das coisas com as propriedades de atores sociais, e o fato de que todas essas coisas e atores têm trajetórias múltiplas e desiguais...

Isso também nos traria de volta ao seu trabalho mais recente, que tem um componente militante ausente nos seus trabalhos anteriores. O senhor poderia falar um pouco sobre esse trabalho, que tem como tema central as desigualdades em Mumbai?

- Claro. Bem, uma vez mais, creio que há, no trabalho da maioria das pessoas, continuidades, mas há, também, algumas obsessões recorrentes, algumas das quais podem ser bastante temáticas. No meu caso não são tão temáticas assim; elas são mais problemáticas. Quero dizer com isso que há algo subjacente aos temas que é recorrente e, no meu caso, isso tem a ver com o movimento, com a materialidade, com a tensão entre a imaginação e a aspereza do mundo externo, que me recuso a semiotizar excessivamente. Ou seja, se semiotizamos até o fim 
da tensão, temos representações por baixo de representações, e essa não é a minha leitura do mundo.

Gosto da ideia de perseguir a terceira via. Eu percebi que a moradia em Bombaim seria um grande tema. Em 1993, tive a sorte de estar na África do Sul na semana em que Mandela assumiu o poder. Nessa ocasião, constatei que metade das histórias sobre as esperanças daquela transição estava relacionada a questões de moradia. Perguntei para mim mesmo: o que significa isso? Moradia, privadas, esgoto não são coisas que vêm em mente quando pensamos no glamour de uma revolução racial nacional. Porém, como eram esses os temas em discussão, deveria haver então alguma coisa ali. Eu rapidamente percebi que tinha a ver com o espaço e a segregação na África do Sul. Mais tarde, no final dos anos 90, em um contexto completamente diferente, deparei-me com a mesma coisa em Bombaim. Esse era, também, o problema de Bombaim.

Se eu tivesse que dizer uma coisa que definisse pobreza e exclusão e a economia da criminalidade e dos investimentos, da especulação, tudo poderia ser sintetizado em uma única palavra: moradia, e, por extensão, mercado imobiliário. Moradia e mercado imobiliário porque muitos aspectos da moradia não remetem exatamente ao mercado imobiliário porque há pessoas morando nas ruas etc. E isso, mais uma vez, representa uma continuidade com o meu trabalho porque a moradia é, acima de tudo, algo objetificado, mas também intimamente conectado à sociabilidade.

Foi o que percebi, depois de Modernity at Large, a partir das críticas que recebi por ter desenhado, supostamente, uma imagem demasiadamente otimista dos fluxos globais, como se eles fossem abertos a todos. Acho que uma leitura um pouco mais cuidadosa do livro demonstra que, entre outros pontos, faço uma discussão sobre exploração sexual, e que as leituras sobre nacionalismo e relações de gênero, por exemplo, são mais pessimistas. Talvez as pessoas tenham lido o livro desse modo porque ele não aborda diretamente a distribuição da desigualdade como tal. Nesse sentido, o estudo da moradia me forçaria a confrontar a relação entre as práticas por meio das quais as localidades são produzidas do modo como discuto em Modernity at Large, e as duras condições em que a localidade é produzida.

Questões materiais como a moradia sempre me conduzem de volta à $A$ vida social das coisas, porque impõem a questão sobre o que as pessoas querem quando buscam moradia. O que elas buscam? É apenas algo entre elas e o mundo exterior ou há outro tipo de investimento, como James Holston encontrou na periferia de São Paulo? Na realidade, há certas práticas por meio das quais as pessoas se colocam por inteiro, mesmo nas moradias mais informais. Eé importante entendermos como elas fazem isso. $\mathrm{O}$ trabalho com a moradia proporcionou-me também uma compreensão maior sobre o que está em jogo, não só na produção 
da localidade, mas em condições de pobreza extrema. Trata-se de produzir o que chamo, às vezes, de "política da paciência", ou seja, a espera por uma casa, o trabalho envolvido nessa espera, ou a política de esperança, de aspirações. Todos esses são aspectos de uma mesma coisa, e nos trazem de volta à questão de como, em um mundo de limites extremos na distribuição das coisas - nesse caso, da moradia -, é possível a mobilização.

Como é possível uma política de esperança em situações que seriam em princípio de falta, ou de desagregação, ou mesmo de sangria. Essa política de esperança surge justamente nesses lugares, como pude observar em função do meu interesse contínuo em temas como minorias, exclusão, violência étnica e o ímpeto global no sentido de redução, subtração, anulação. Nas comunidades mais pobres, as duas coisa se encontram, ou seja, é nas comunidades mais pobres que as políticas de aniquilamento ou etnocídios são não criadas, mas encenadas. E são essas mesmas comunidades que mobilizam a resistência a esses ímpetos, o que nos leva a indagar por que isso ocorre. Acho que vale a pena trabalhar nessa perspectiva, ou seja, perguntar, onde estão os pontos de virada, quando eles acontecem, por que um lugar como Bombaim, onde as condições físicas são extremamente duras, não produz uma violência social cotidiana como aquela que acontece, por exemplo, em São Paulo ou no Rio de Janeiro?

Para mim, essa questão é muito importante, não porque eu ache que na China, em Israel ou no Rio as pessoas falem mais de violência, ou experimentem mais medo, e não só os ricos. Nós sabemos que o medo que existe em um lugar como Bombaim é de outra ordem, e há razões para isso. Mas por que, em condições marcadamente similares - crime organizado, especulação, escassez habitacional, corrupção política, desigualdades gritantes, quase-democracias - a violência corporal e contra a pessoa é impressionantemente diferente em Bombaim com relação a outros lugares? Lá você pode pegar um táxi depois de meia-noite e rodar pela cidade com um mínimo de atenção, coisa que eu não faria nem aconselharia ninguém a fazer em São Paulo, ou mesmo em Nova Delhi. Ou seja, mesmo sem sair da Índia, temos contextos marcadamente diferentes.

Na sua opinião, há mesmo uma grande diferença entre Delhi e Mumbai nesse aspecto? Obviamente, o caminho mais fácil e usual para se explicar por que Rio e Foanesburgo são cidades violentas em contraposição às cidades indianas passa pelo acionamento da chave da religião.

- Eu diria que essa explicação não faz sentido. A realidade é muito mais complicada e eu não sei a resposta, mas, de todo modo, diria que não é a religião. Como você sabe, essas diferenças são muito mais sutis. A religião está presente em Bombaim e em outras cidades. Se você perguntar para qualquer mulher, rica 
ou pobre, que tenha vivido nas duas cidades, ela lhe dirá imediatamente qual das duas prefere.

\section{Curioso... Eu me senti bem mais confortável em Bombaim do que em Delhi...}

- Ah, sim, os visitantes têm, em geral, essa percepção, mas as pessoas que vivem lá têm que fazer ajustes constantes. Por exemplo, evitam viajar à noite, coisa que em Delhi é bem mais tranquilo. Isso tudo tem a ver com questões demográficas, com a natureza da força de trabalho masculina em Delhi, a natureza da polícia. Ninguém tem uma resposta completa e satisfatória, porém o efeito final é claro: as coisas mudaram, Bombaim tem mais crimes, mais violência. De todo modo é trivial, se levarmos em conta as condições.

Eu me interesso particularmente pelo aspecto da materialidade. Por exemplo, nesses trens cheíssimos em que as pessoas transitam, milhões de pessoas viajam ali em situações extremamente adversas. É como os trens do norte do Japão, mas com a economia de Johanesburgo ou Rio... Então por que há tão pouca violência social? Estou convencido de que não se trata de algo misterioso do tipo "propriedade da cultura" ou "não-violência indiana". Trata-se de algo específico a certas localidades, específico em relação à história de Mumbai versus a de Calcutá, versus a de Madras, para nos atermos apenas à Índia. Não conheço nenhum artigo que realmente tenha conseguido capturar isso.

Claro que se pode dizer que é o cosmopolitismo de Bombaim, mas o que é a causa e o que é o efeito? Podemos dizer que o cosmopolitismo é a causa, mas podemos dizer também que é o efeito de alguma outra coisa. Mas o que é essa "outra coisa"? Não se pode dizer que seja "tolerância" porque novamente estaremos apenas renomeando o fato. Não se pode dizer "religião" porque não é diferente de outros lugares. Pode-se falar em comércio e na interdependência das raízes; porém, se faz sentido falar em uma relação entre comércio e etnicidade, essa relação não existe entre crime e etnicidade: o crime não conhece etnicidade. Em geral, o crime não tem nada a ver com hindus ou mulçumanos. É algo distinto. Então por que o crime violento? Crime contra a propriedade? Crime contra a integridade física? Não sei tenho resposta a essa pergunta, mas creio ser uma pergunta importante a se fazer em qualquer megacidade.

Se tomarmos Rio e São Paulo, duas cidades nas quais estive muito brevemente, as diferenças existem e é preciso ver sob que condições e em que lugar, em que setor, em que momento histórico acontecem coisas específicas. Tomemos como exemplo as crianças envolvidas com o crime. Em Bombaim, há crianças envolvidas com pequenos furtos, mas de modo bastante restrito. Dificilmente tem-se uma criança ameaçando alguém com uma faca. Há crianças roubando, mas aquela fronteira (a do furto violento) é cruzada apenas em alguns lugares e em certos momentos. Tenho certeza de que no Rio e em São Paulo acontecem cri- 
mes violentos em determinados lugares, e não em outros, em alguns momentos sim, mas em outros não. Trata-se, com certeza, de um tema central para as ciências sociais porque não se trata de algo generalizável.

Voltando ao exemplo da Índia. Não tenho dúvidas de a Índia é extremamente violenta. A violência doméstica é um problema seríssimo, mas as pessoas não fazem propaganda disso. Mulheres são espancadas e mal-tratadas todos os dias, o tráfico sexual é alto, enfim há violência de fato. Em contraposição, não há uma forma particular de perigo no espaço público. Trata-se, portanto, de uma questão refinada.

Gostaríamos de encerrar esta conversa falando um pouco mais sobre o que o senhor chama de globalização a partir de baixo. Temos, como ponto de partida, um exemplo interessante: em 2006, um jovem empresário inglês esteve no Rio e fez o chamado tour da Rocinha. Essa experiência o inspirou a dar início a atividades turísticas em Dharavi, a maior favela de Mumbai. Nós exportamos a tecnologia do tour de favelas para a India!

- Imagine só! Dharavi, não sei se vocês sabem, é um espaço de tensão, um território de disputas, que se referem, sobretudo, ao mercado imobiliário. Dharavi está sendo alvo de um enorme esforço conjunto entre Estado e mercado privado, visando sua desocupação. Para lhes dar a dimensão econômica da disputa, é bom lembrar que Dharavi é habitada por muitas pessoas pobres - apesar de nem todas serem igualmente pobres - que ocuparam terras centrais com valor imobiliário equivalente às de certas partes de Nova Iorque, algo entre $\$ 1500 \mathrm{e}$ \$2000 por pé quadrado. Há um milhão de pessoas vivendo ali e não se pode simplesmente removê-las - a Índia não é o Zimbabwe. Lá, como vocês sabem, o [Robert] Mugabe [presidente do país] tentaria fazer isso, mas na Índia não se pode simplesmente trazer soldados para expulsar as pessoas. Pode-se fazer muitas coisas, as pessoas são maltratadas e abusadas, mas há resistência em Dharavi.

Além disso, trata-se de um local não apenas de moradia, mas também de produção.

- Esse é o ponto-chave. Em Dharavi, cada unidade habitacional é também uma unidade produtiva, que produz couro, cerâmica, tecidos, alimentos etc. Há gente vendendo coisas na rua, fritando comida... Faz sentido morar ali porque ali estão as oportunidades de trabalho. É uma loucura imaginar que um lugar já tão agitado possa abrigar atividades turísticas, e não apenas por questões de segurança. Comparando-se com as favelas, onde há criminosos ostensivamente armados e conflitos entre bandidos e polícia, Dharavi não é tão ameaçadora, mas ainda assim corre-se o risco de ser assaltado, há venda ilegal de bebida e coisas do tipo. Mas a questão principal em Dharavi hoje é a da concorrência imobiliária. Trava-se uma luta sobre o espaço e a moradia. 
Nesse sentido, Dharavi tem um pouco de Bombaim e de outros lugares onde a questão da habitação e do mercado imobiliário assume contornos completamente irracionais. De um lado estão o mercado imobiliário, as construtoras globais e os especuladores, que se aliaram ao Estado, à administração e às construtoras locais; de outro, estão os pobres que têm direito ao uso do solo porque, na verdade, o solo foi criado a partir do acúmulo contínuo de lixo e dejetos. Não se trata, portanto, de uma terra que existia e foi ocupada, mas de uma localidade produzida pelos que ali vivem. Dharavi nos coloca diante da capacidade produtiva que os moradores de áreas precárias têm e que ecoa na economia do país como um todo. Se Dharavi desaparece, desaparecem também milhares de outras coisas. Esse é o dilema. 